\title{
Procedimiento para el acceso a la información pública en Nicaragua
}

Uriel Pineda Quinteros

Centro Nicaragüense de Derechos Humanos - CENIDH, Managua. Correo electrónico: Uriel pineda@hotmail.com

EL ESTUDIO EXPLORA EL TEMA DEL ACCESO A LA información pública en Nicaragua. Inicia con una caracterización del derecho de acceso a la información para luego abordar su parte procesal o adjetiva en la vía administrativa y la vía judicial.

Palabras clave: acceso-información pública / Nicaragua

\section{Introducción}

Cuando oímos hablar de la Ley de Acceso a la Información nos viene a la mente frases como: "Ya tenemos la llave"; "Secretismo gubernamental"; y la pregunta más recurrente en las conferencias sobre el tema “¿La cooperación venezolana entra ahí?”. Desde el año 2003 la Fundación Violeta Barrios de Chamorro ha impulsado una fuerte campaña orientada en un primer momento a la aprobación de una Ley de Acceso a la Información Pública, y a partir de mayo de 2005, a la promoción y monitoreo de su aplicación.

El presente estudio desarrolla tres aspectos alrededor de la temática. El primero de ellos está referido a caracterizar derecho de acceso a la información, concepto, naturaleza, sobre qué versa el derecho y suspensión del mismo. Las otras dos temáticas abordan el derecho de acceso a la información pública en su parte procesal o adjetiva, primero en la vía administrativa que parte de la solicitud ante la dependencia del Estado hasta la resolución de la Oficina de Coordinación de Acceso a la Información, según sea el caso; y segundo, la vía judicial por medio del control de legalidad que realiza la Sala de lo Contencioso Administrativo de la Corte Suprema de Justicia.

\section{Caracterización del derecho de acceso a la información}

Para la Ley de Acceso a la Información Pública ${ }^{1}$ (LAIP) el derecho de acceso a la información pública es: "El derecho que tiene toda persona para acceder a la información existente en poder de las entidades sujetas" a la regulación dee esa Ley.

La definición resulta un tanto elemental. Pierini y Lorences (1999:21) conciben este derecho como: 
...el reconocimiento formal de la aptitud de toda persona de buscar, requerir y recibir información pública certera sobre una muy variada clase de cuestiones que se encuentran en todo tipo de archivos gubernamentales, y que se refiere a la actividad funcional de los distintos poderes del Estado y/o aquellos entes públicos, privados o mixtos donde existan intereses públicos comprendidos; todo ello de conformidad a los actos de gobierno.

En términos más sencillos, el derecho de acceso a la información es la facultad que tienen las personas de solicitar - sin importar con qué fin-y recibir, de la Administración Pública, todo tipo de información en poder del Estado, de manera oportuna y sin mayor restricción que la suspensión del derecho debidamente fundada.

Lo importante es poder identificar, como elemento constitutivo, que es una facultad que le asiste a cualquier persona sobre cualquier información en poder del Estado. Dicho derecho implica la correlativa obligación del funcionario a suministrar la información requerida y dentro del tiempo oportuno que determina la Ley al efecto. Asimismo, no puede condicionarse la entrega de la información al uso que le dará el requirente, y por último, ese derecho puede ser suspendido por la autoridad por razones fundadas y permitidas por la Ley.

El derecho de acceso a la información pública tutela el principio de la Publicidad de los Actos de Gobierno (Pierini y Lorences, 1999:197), mismo que encuentra amparo en nuestra Constitución Política en el Arto. 131 al establecer la obligación para los funcionarios públicos de informar de su trabajo y actividades oficiales, y en consecuencia se torna el fundamento legal del derecho en cuestión.

Otra naturaleza atribuida a este derecho es que deriva del derecho a la información porque enmarca los elementos de buscar y recibir información. El problema es que el derecho a informar es garantía reconocida para el ejercicio del periodismo, sin perjuicio de que se extienda el derecho a las personas en general en virtud de la igualdad ante la ley.

Tampoco puede considerarse una modalidad del derecho de petición del Arto. 52 de la Constitución Política, ya que este derecho es más amplio y abarca denunciar anomalías y hacer críticas constructivas. De igual manera, no es participación ciudadana debido a que este derecho procura el involucramiento de la población en el diseño y aplicación de políticas públicas. El derecho de acceso a la información pública es simplemente auditoria social atribuida a cualquier persona natural o jurídica.

El derecho de acceso a la información no versa sobre la entrega masiva del Diario Oficial, ni información complementaria de la allí contenida, sino un acceso completo a la información pública y no meramente formal o indicativa (Pierini y Lorences, 1999:217). Dicho de otro modo, la información pública que busca el derecho de acceso a la información comprende el quehacer material de la Administración Pública en el ejercicio de sus funciones.

Para el ejercicio del derecho resulta irrelevante qué dependencia del Estado la posea, de qué se trate 0 en qué forma se encuentra almacenada la información (Pierini y Lorences, 1999:219), por tal razón, el funcionario encargado no debe imponer restricciones relacionadas a las circunstancias señaladas. 
Esta Ley regula el acceso a la información pública que genera, obtiene y almacena la Administración Pública en el ejercicio de sus atribuciones y funciones. De igual manera, comprende la información que contiene interés público, que según Ernesto Villanueva "puede entenderse como el conjunto de datos y hechos ordenados que tienen como propósito servir a las personas para la toma de decisiones, de manera que se enriquezca la convivencia y participación democrática" (Villanueva, 2003:LXXXIV).

En virtud del interés público se afecta a empresas estatales y mixtas, empresas concesionarias del Estado en lo concerniente a la concesión, empresas o entidades subsidiadas directamente en cuanto al destino de los fondos, y empresas u organismos que reciben subsidios indirectos o beneficios fiscales en cuanto al monto y legalidad de los mismos. Quedó excluida del ámbito de aplicación de la Ley la denominada información privada, que es la referida a información de las personas.

No obstante, pese a las bondades de la LAIP no existen derechos absolutos y el derecho de acceso a la información no es la excepción. Un límite que tiene es que cabe la suspensión, o dejar sin efecto el derecho de acceso a la información mediante una resolución permitida por ley que justifique la necesidad de hacerlo en un lapso de tiempo determinado. Una vez que ya no concurran las circunstancias que motivan la suspensión y/o se cumpla el tiempo por el que fue reservada, se puede hacer solicitud de la información, al menos que exista una prórroga de la reserva.

El acuerdo que califique como reservada una información debe expresar las razones de la reserva que deben coincidir con las permitidas por la Ley y, adicionalmente a ello, se debe establecer el tiempo de la reserva. Si las razones que motivaron la reserva desaparecen, no tiene objeto mantener la información en esa calidad y por lo tanto debe ser de libre acceso al público. Por el contrario, si se vence el tiempo de la reserva y las causas que la motivaron persisten, el titular de la entidad cuenta con la potestad de prorrogar la reserva ${ }^{2}$.

Es importante destacar que la suspensión no puede ni debe tener un carácter indefinido, pues el acuerdo que califique como reservada indefinidamente sería arbitrario por no estar permitido por la LAIP. Además, sería inconstitucional porque violentaría el principio de la Publicidad de los Actos de Gobierno. Caso distinto es la información a la que no se tiene acceso pese a ser pública.

La suspensión o reserva se fundamenta en el principio de la prueba del daño que no es más que la facultad reconocida a favor de la autoridad para restringir el acceso a información pública. La suspensión procede cuando se lo permita la Ley, cuando el suministrar la información afecte el interés público y por último, cuando el daño que se produzca al facilitar la información sea mayor al interés público de conocer la información. Todo ello debe ser debidamente fundado.

Según Villanueva (2003:LXIV), "el principio de la prueba del daño tiene como propósito acortar al máximo las posibilidades de ejercicio discrecional en la clasificación de la información y, por ende, ofrecer mayores garantías al derecho de acceso a la información pública a favor de las personas". 


\section{Procedimiento de acceso a la información pública en la vía administrativa}

El procedimiento para el acceso a la información pública en Nicaragua inicia con la solicitud. Se puede considerar como un acto procesal. Sendra et al. (1991:235) definen los actos procesales como aquellos realizados por los sujetos del proceso que afectan la constitución, desarrollo, modificación o terminación de la relación jurídica procesal.

La solicitud da inicio al procedimiento de acceso a la información. Es considerado como un presupuesto del recurso administrativo, el caso de que la solicitud no haya sido tramitada satisfactoriamente. En otras palabras, la resolución que deniega la solicitud es el acto administrativo a atacar. En el supuesto de que se resuelve satisfactoriamente la solicitud, esto también se considera un acto procesal ya que pone fin a la relación jurídico procesal.

La legitimación es la facultad que la LAIP les otorga a las personas para hacer uso de su derecho de acceso a la información en aras de obtener una mayor transparencia en la gestión administrativa. Es amplia, no hay ninguna restricción legal para hacer la solicitud de acceso a la información pública. Es un instrumento que le permite a la persona común ejercer un control sobre la gestión administrativa del gobierno y demás poderes del Estado.

La solicitud es un acto potestativo que le corresponde al particular y obliga a la entidad a darle seguimiento bajo las directrices establecidas en la LAIP.

Existen tres formas de hacerlo:

1. De forma escrita. Se hace por medio de los formatos que se habilitarán al efecto.

2. De forma verbal. En tal caso el funcionario llenará el formato por la persona

3. Por correo electrónico. Siempre la solicitud se hará ante la Oficina de Acceso a la Información Pública (OAIP) de la entidad correspondiente. ${ }^{3}$

La solicitud debe contener al menos los requisitos siguientes: ${ }^{4}$

1. Nombre de la autoridad a quien se solicita la información.

2. Nombre, apellidos, generales de ley y domicilio del solicitante.

3. Cédula de identidad o cualquier tipo de identificación, o el número de las mismas. Los menores de 16 años podrán presentar su Partida de Nacimiento. Los extranjeros podrán presentar Pasaporte vigente, Cédula de Residencia o los números de las mismas.

4. Descripción clara y precisa de la información solicitada.

5. Dirección postal o correo electrónico señalado para recibir la información o notificaciones.

Las facilidades que permite la LAIP en cuanto a la asistencia letrada, uso de medios informáticos y las múltiples formas de identificar al solicitante son una característica del Proceso Administrativo denominada informalismo, que es una garantía a favor de los particulares que excusa la observancia de elementos formales, como describe Picone (1982:166). 
No obstante, esa generosidad del legislador resulta incorrecta porque permite identificarse con documentos distintos del documento oficial -para el caso de ciudadanos nicaragüensese incluso con sólo el número de estos, lo que trae como consecuencia la imposibilidad de identificar verdaderamente al solicitante. En igual sentido, permitir que los menores de 16 años se identifiquen con su Partida de Nacimiento es incorrecto porque la naturaleza de dicho documento es una certificación y no un documento de identificación.

Otro aspecto a destacar es el hecho de que la solicitud contenga las denominadas generales de ley, mismas que comprenden el estado civil de una persona. Surge entonces la interrogante de ¿̇con qué finalidad la OAIP recauda esa información?

La admisibilidad de la solicitud es el primer acto que realiza la autoridad encargada de la OAIP. Consiste en un examen de procedencia de la solicitud interpuesta por el particular en donde se puede admitir, denegar o mandar a subsanar dicha solicitud dentro de los tres días después de interpuesta la solicitud.

Si se admite, se continúa con el procedimiento dándole trámite a la solicitud y además se le notifica al solicitante, informándole también cuándo se le dará respuesta a la misma. Cuando se deniega la solicitud, se debe a la calificación de la información como reservada o a que la dependencia no posee la información.

Para el caso de que la información solicitada se encuentre calificada como reservada, el encargado de la OAIP se lo hará saber al interesado y le advertirá además si la reserva es total o parcial. En este último caso se podrá tramitar la solicitud en razón de la información no calificada como reservada. En caso de que la totalidad de la información sea reservada, se declara inadmisible la solicitud y se le advertirá de los derechos de apelación -ante quién y en qué término- que tiene el interesado, culminando así el trámite en la OAIP de la entidad.

En el supuesto de que la información no se encuentre en la dependencia, existe la obligación del encargado de la OAIP de advertir al interesado en qué dependencia se encuentra la información que solicita. Esto debe de entenderse siempre que sea posible, claro está.

La subsanación de la solicitud tiene lugar cuando la información solicitada no se hizo de forma clara o comprensible, se le informa al solicitante para que haga las aclaraciones al respecto. Por otra parte, existe la obligación de que la OAIP cuente con un índice de la información que posee la institución. Éste debe ser facilitado a los usuarios del servicio para que su solicitud sea lo más precisa posible.

La publicación en La Gaceta Diario Oficial o cualquier medio de difusión de la información solicitada, no es causal para declarar inadmisible la solicitud, pero sí se debe advertir de la publicación al solicitante.

La LAIP establece un procedimiento de forma general que no determina con precisión los pasos que debe realizar el encargado de la OAIP de cada entidad para dar respuesta a la solicitud de acceso a la información. Debido a que esta ley es aplicable a todas las 
dependencias del Estado, es recomendable que cada poder de Estado u órgano de creación constitucional, de conformidad con sus particularidades, determine el procedimiento a seguir considerando aspectos mínimos.

La tramitación es la serie de procedimientos que realiza la OAIP como órgano de enlace para obtener de las demás dependencias de la entidad la información que se encuentra a su cargo y fue solicitada en virtud del ejercicio de acceso a la información pública de un particular.

La LAIP establece que la OAIP debe entregar la información solicitada de forma inmediata o a más tardar dentro de 15 días. ${ }^{5}$ Esto sólo es posible si la OAIP cuenta con una base de datos mínima que contenga adicionalmente a la información descrita en el Arto. 20 de la LAIP.

El encargado de la OAIP tiene la facultad de requerir a otras dependencias de la entidad, la información que se encuentre en poder de ellas y que además le haya sido solicitada. Una vez hecha la solicitud por parte del encargado de la OAIP a la dependencia de la entidad que conserva la información requerida, el encargado de esta última debe remitir la información de manera inmediata y en su defecto hacerlo dentro de un plazo prudencial que permite cumplir con lo establecido en la LAIP.

Si al encargado de la dependencia de la entidad a cargo de la conservación de la información no le es posible entregar la misma en ese plazo prudente por necesitarse más tiempo para reunir la información requerida, debe informar de la necesidad de prórroga al encargado de la OAIP, quien a su vez y según lo estime conveniente, podrá hacer uso de la facultad de prórroga que le confiere la LAIP y notificar al interesado de ello.

Una vez que la información requerida haya sido reunida por el titular de la dependencia de la entidad que tiene a su cargo el resguardo de la información, y previo al vencimiento del plazo establecido para ello, le remitirá la información solicitada al encargado de la OAIP sin mayor retraso.

El encargado de la OAIP debe examinar la correspondencia entre la solicitud de requerimiento y la información remitida, pudiendo hacer solicitudes dentro de nuevos plazos al titular de la dependencia de la entidad que tiene a su cargo el resguardo de la información para subsanar el vacío, esto debido a que él responde por la entrega de la información

Una vez que haya sido remitida la información al encargado de la OAIP y que a su vez éste coteje la correspondencia con la solicitud hecha por el particular, notificará a este último para que pase retirando la información que solicitó y advertirá de su derecho de apelación ante la Oficina de Coordinación de Acceso a la Información Pública (OCAIP) de cada poder del Estado si su solicitud no fue resuelta de manera satisfactoria.

La advertencia de apelación sólo cabe en los casos de dependencias de los poderes del Estado, ello debido a que la Ley faculta únicamente a los poderes del Estado a tener OCAIP y como consecuencia de esto, el encargado de la OAIP de los órganos de creación constitucional deberá advertir que la inconformidad respecto de la información brindada es recurrible ante la Sala de lo Contencioso-Administrativo de la Corte Suprema de Justicia (SCA CSJ). 
La información estará a disposición del solicitante, él determinará si la quiere en documento físico. En este supuesto deberá pagar el costo de la impresión o copiado según el caso. No puede considerarse como denegada la solicitud cuando el particular no pague los costos de impresión o copiado, que no deben exceder al precio de costo. En todo caso, la obligación de entregar la información termina con el hecho de ponerla a disposición del interesado

La inconformidad con la respuesta a la solicitud abre la posibilidad de apelar ante la OCAIP. Según el caso, dicha apelación da inicio al recurso administrativo que tiene como fundamento el control jurídico. Picone (1982:159) sostiene que el control jurídico es una potestad administrativa de revisar los propios actos, por iniciativa propia o a instancia de parte interesada. También puede ser el ejercicio de acciones o recursos judiciales previstos en la Ley para que la administración y administrados diriman la legitimidad de un acto administrativo siendo necesario en este caso el agotamiento de la vía administrativa.

Es la primera hipótesis la que me interesa recalcar. Si la administración cuenta con una facultad que le habilite a revisar su actuar, deja a salvo posibles afectaciones a derechos de los particulares y es esa la razón en que se fundamenta el normar los recursos administrativos.

Los recursos administrativos son definidos por Rafael Martínez (2000:417) como: "El medio de defensa establecido en la ley, a favor de los gobernados para que la administración pública revise un acto administrativo que ellos consideran ilegal, quedando aquella obligada a anularlo, modificarlo o confirmarlo".

Se puede decir que es un medio legal a favor de los particulares que les permite impugnar una resolución que les afecte y obliga a la entidad a darle respuesta a la solicitud, todo ello siempre en sede administrativa. La Ley debe de regular el procedimiento de tramitación y por supuesto, el tiempo para emitir la resolución.

Un presupuesto del recurso administrativo es la existencia de una resolución que además afecte al particular que recurre. Una vez interpuesto el recurso en contra de la resolución, existe la obligación por parte de la entidad de:

1. Modificarla, lo que conlleva que la afectación a la resolución inicial sea parcial.

2. Anularla, lo que implica que la resolución queda sin efecto alguno.

3. Confirmarla o no darle cabida al recurso, consecuentemente dejar intacto los alcances originales de la resolución.

Andrés Serra Rojas, citado por Rafael Martínez (2000:417) determina la existencia de elementos característicos de los Recursos Administrativos que son:

1. La existencia de una resolución administrativa.

2. Un particular que interponga el recurso.

3. Que exista una afectación al particular.

4. Debe estar establecido en la ley.

5. La autoridad ante quien se interpone. 
6. Plazo para interponerlo.

7. Requisitos de forma.

8. Procedimiento adecuado.

9. Obligación de la autoridad de dictar resolución.

\section{Apelación ante la Oficina de Coordinación de Acceso a la Información Pública}

Para interponer un recurso administrativo en contra de la OAIP ante la OCAIP existen presupuestos procesales. Para Sendra et al. (1991:289), los presupuestos procesales son: "aquellos elementos que han de concurrir con anterioridad al ejercicio del derecho de acción, a fin de que pueda constituirse válidamente dicha relación; ellos se deben fijar en clara contraposición con las reglas puramente relativas a la marcha del procedimiento que estén previamente determinadas, los requisitos de admisibilidad y las condiciones previas para la tramitación de toda relación procesal”. Dicho de otra manera, son el historial o antecedente necesario para llegar a una determinada etapa del procedimiento.

Para el recurso en cuestión nos interesan los supuestos en los cuales tiene lugar la interposición y la temporalidad del mismo. En tal sentido, los supuestos en que procede el Recurso de Apelación ante la OCAIP de cada poder del Estado son: ${ }^{6}$

1. Resolución negando el derecho de acceso a la información. En este caso debe ser fundada bajo pena de nulidad y se debe de hacer a más tardar dentro de los tres días posteriores a la interposición de la solicitud.

2. Por silencio administrativo. El caso se presenta cuando transcurrió el plazo establecido en la LAIP y la OAIP no brindó respuesta a la solicitud. Aquí el silencio administrativo tiene un valor positivo y se considera como aceptación de lo pedido. El recurso versará únicamente sobre la entrega de la información.

En lo que concierne a la temporalidad, el recurso debe interponerse dentro de los seis días después de la fecha de notificación de la resolución que establece como denegada la solicitud de acceso a la información. Para el caso del silencio administrativo, el término será seis días después del vencimiento del plazo de la admisión de la solicitud.

Cumplidas esas condiciones, la OCAIP cuenta con 30 días para resolver el recurso. ${ }^{7}$ Puede resolver confirmando, revocando u ordenando la entrega de la información. En el primer caso constata que la resolución denegando la información fue tomada en base a ley y está correcta. En el segundo caso dispone que la apreciación para fundamentar la negativa de la solicitud por parte del encargado de la oficina de acceso a la información de la entidad no sea correcta y manda a que se entregue la información.

El último supuesto no versa sobre el fundamento de la resolución y parte de la idea que el silencio administrativo constituyó un derecho a favor del particular y manda a que se entregue la información, excepto si está clasificada como reservada.

En términos generales podemos señalar que el hecho de que el particular ejerza su derecho de apelación ante la OCAIP supone el agotamiento de la vía administrativa. Sin embargo, 
no es un requerimiento obligatorio hacer uso del recurso de apelación para agotar la vía administrativa. En tal sentido, el agotar la vía administrativa bajo este supuesto, haciendo uso de la apelación, es opcional. El particular, ante los mismos supuestos de negativa de acceso a la información y silencio administrativo, puede recurrir ante la SCA CSJ de conformidad a lo establecido en el Arto. 37 de la LAIP.

En la LAIP existen incongruencias respecto del recurso administrativo. El encargado de la OAIP se encuentra bajo dependencia directa de la máxima autoridad de la entidad ${ }^{8}$. En cambio, la OCAIP de cada poder del Estado funge como órgano revisor de las resoluciones emitidas por la primera. No existe una relación jerárquica funcional. En consecuencia, rompe con el concepto de recurso administrativo porque está revisando un acto administrativo que no emitió.

Por otra parte, el hecho que el agotamiento de la vía administrativa pueda concluir o no con el Recurso de Apelación y se pueda recurrir directamente a la SCA CSJ, coarta la atribución de la Administración Pública de revisar los actos administrativos. Esto debido a que la Ley deja de forma opcional que el particular que solicita la información impugne la resolución emitida por la OAIP ante la OCAIP o recurra directamente ante la SCA CSJ y que este último órgano sea el que determine si se vulneró o no el derecho de acceso a la información pública.

\section{Procedimiento de acceso a la información pública en la vía judicial}

\subsection{Capacidad y legitimación}

La capacidad en su sentido más básico debe ser entendida como la facultad o aptitud para realizar determinado acto. En la Ley de Regulación de la Jurisdicción de lo ContenciosoAdministrativo (LRJCA) se establece que tienen capacidad los particulares, sus mandatarios y los mayores de 15 años con interés legítimo. ${ }^{9}$

Sendra et al. (1991:187) definen la legitimación como:

...la específica situación jurídica material en la que se encuentra un sujeto, o una pluralidad de sujetos en relación a lo que constituye el objeto del litigio de un determinado proceso; legitimación, en definitiva nos va a indicar en cada caso quiénes son los verdaderos titulares de la relación material que se intenta dilucidar en el ámbito del proceso; quiénes son los sujetos cuya participación procesal es necesaria para que la sentencia resulte eficaz.

Para interponer un recurso ante la SCA CSJ se requiere que sea hecho por el particular que hizo la solicitud ante la OAIP de una entidad y que ésta a su vez le haya resuelto en forma negativa o simplemente no haya dado respuesta a la misma.

\subsection{Presentación de la demanda y su contenido}

González Pérez (1992:203) nos explica que la pretensión es el objeto de la demanda. La demanda puede ser entendida como el escrito de postulación de la parte actora mediante 
la cual introduce su pretensión, referida al acto administrativo o disposición que ha sido referida en el escrito en el que se interpone el recurso (Sendra et al., 1991:253).

La demanda se interpone en la SCA CSJ dentro de los 60 días a partir de la fecha de notificación de la negativa de la solicitud de acceso a la información. Para el caso del silencio administrativo, el tiempo se computa desde el vencimiento del plazo para dar respuesta a la solicitud.

La demanda puede hacerse en papel común y debe de contener: ${ }^{10}$

1. Identificación de la SCA CSJ.

2. Nombre, apellidos y generales de ley del actor o su representante.

3. Identificar al órgano contra quien se dirige la acción.

4. Exposición de los hechos con indicación del acto contra el cual se recurre.

5. Fundamento de Derecho.

6. Ofrecimiento de pruebas.

7. Solicitud de que se tenga por ejercida la acción contenciosa-administrativa.

8. Lugar para oír notificaciones.

9. Fecha y hora.

Junto con la demanda se deben presentar documentos que acrediten el interés legítimo del particular. En el caso que nos ocupa se muestra la copia de la solicitud de acceso a la información, descripción o copia del acto administrativo y copia de la demanda.

\subsection{Mediación}

Es la búsqueda de un advenimiento entre las partes que permita una pronta solución al litigio y evite la acumulación de causas en un tribunal. Intenta evitar la retardación de justicia. Tiene su origen en el Arto. 94 de la Ley $260^{11}$ y es retomada por el Arto. 55 de la LRJCA. Debe llevarse a cabo dentro del tercer día de la notificación y de llegarse a un acuerdo terminaría con el procedimiento.

\subsection{Admisión y emplazamiento}

Es posible que la demanda sea presentada en forma defectuosa, en tal caso cabe la subsanación. La SCA CSJ le otorga al demandante un plazo de diez días para subsanar la demanda bajo el apercibimiento de que si no se hace se tendrá como no presentada la misma. ${ }^{12}$

El recurso se considera inadmisible cuando adolece de un defecto procesal insubsanable (González Pérez, 1992:462). El recurso puede ser declarado inadmisible de oficio o a petición de parte por aspectos referidos a la competencia, jurisdicción, prescripción y para casos distintos del nuestro, el no agotamiento de la vía administrativa. Como se exponía con antelación para recurrir ante la SCA CSJ por negativa del derecho de acceso a la información, el agotamiento de la vía administrativa es opcional y a consecuencia de esto no es causal para declarar inadmisible la demanda. 
El emplazamiento para personarse se hace por medio de la notificación de la demanda a la PGR o al representante legal del órgano para que se persone dentro de seis días, de no hacerlo se declarará la rebeldía. El apersonamiento puede hacerse sin esperar emplazamiento para oponerse.

\subsection{Publicación de la demanda y requerimiento del expediente}

Una vez presentada la demanda y sin que las partes hayan llegado a un advenimiento, la SCA CSJ manda a publicar un extracto de la demanda a través de edicto según lo dispuesto en el Arto. 58 de la LRJCA.

El requerimiento del expediente lo hace el tribunal a los funcionarios responsables del acto impugnado tres días después de la publicación de la demanda, teniendo éstos, diez días a partir de la fecha de recepción del oficio para remitirlo. De no hacerlo existe la presunción legal de ser ciertos los hechos que fundan la demanda. ${ }^{13}$

\subsection{Vista al expediente y sus efectos}

Se realiza un vez que la OAIP de la entidad o la OCAIP, según sea el caso, envía el expediente a la SCA CSJ y ésta a su vez se lo entrega al particular recurrente para que lo examine.

Del estudio que haga el particular del expediente puede pedir los informes y documentos administrativos que no se hubieren incluido. ${ }^{14}$ De igual manera, de la vista al expediente puede derivar la ampliación, rectificación y aclaración de la demanda para lo cual el Arto 44 de la LRJCA otorga un plazo de 20 días.

\subsection{Contestación de la demanda y la prueba}

Una vez que finalizó el trámite de la vista al expediente se hace un emplazamiento para contestar la demanda, que no es otra cosa que establecer un término para contestar la demanda que de no hacerse se considera como contestación negativa de los hechos.

La contestación de la demanda debe de contener:

1. Relación de los hechos.

2. Fundamento de hecho y de Derecho.

3. Lista de pruebas.

4. Excepciones e impugnaciones.

La prueba, según Sendra et al. (1991:279), es la actividad impulsada por las partes o incluso por el juez o tribunal, dirigida a lograr el convencimiento del juzgador acerca de la veracidad de las afirmaciones fácticas realizadas normalmente por las partes y excepcionalmente por el órgano judicial -como es el caso de las diligencias para mejor proveer-y que integran el objeto del proceso.

El Procedimiento Contencioso-Administrativo de Nicaragua contempla la libertad probatoria bajo las únicas condicionantes de licitud en la obtención de la prueba e incorporación de 
conformidad al procedimiento. Es decir, haber sido ofrecidas en el escrito de demanda o contestación del mismo. En idéntico sentido, la SCA CSJ puede limitar la prueba que estime como abundante, repetitiva o notoria. ${ }^{15}$

\subsection{Vista general del juicio}

Tiene lugar después de la contestación de la demanda. Se realiza un pronunciamiento admitiendo las pruebas, poniendo a disposición las mismas y precisando la fecha y hora de la celebración de la vista general de conformidad al Arto. 77 de la LRJCA en un plazo no mayor de diez días.

Llegada la fecha, la vista general inicia cuando el presidente de la SCA CSJ la declara abierta. Comienza el debate con los alegatos del actor en los que hace una relación sucinta de su pretensión y posteriormente tiene intervención la parte demandada. La recepción de la prueba tiene lugar de manera inmediata si fue aceptada y el presidente de la SCA CSJ está obligado a hacer una breve relación.

Hecho eso, se procede a los alegatos de conclusión para que las partes de viva voz hagan sus alegatos conclusivos. Por último el presidente de la SCA CSJ da por terminada la vista general y señala fecha y hora para celebrar la audiencia oral y pública en un plazo no mayor de 15 días para dar a conocer la sentencia. De todo lo expuesto se levanta un acta que contenga un resumen de las peticiones y alegatos.

\subsection{Sentencia}

En palabras de Sendra et al. (1991:423), "es la resolución judicial que constituye normalmente el acto de finalización del proceso de cognición, en cualquiera de sus instancias, y mediante el cual el juez o tribunal, de forma motivada y en aplicación del ordenamiento jurídico decide satisfacer o dejar insatisfecha las pretensiones y resistencias deducidas por las partes".

Tal como lo describe el concepto puede ser estimatoria. En ese caso, obliga al encargado de la OAIP de la entidad a entregar la información que fue requerida por el particular. También la Sentencia puede ser desestimatoria, es decir, que la Sala declara sin lugar la demanda por encontrar que el acto o resolución que deniega el acceso a la información está ajustado a Derecho.

\section{Conclusión}

Concluyo el presente trabajo señalando que si una persona quiere tener acceso a una información pública en particular y su solicitud no encuentra eco en las autoridades, debe armarse de mucha paciencia y prepararse para iniciar todo el proceso descrito. Para agravar ese peregrinaje, hay que sumar el hecho de que no todas las instituciones del Estado han creado las OAIP. Aunque esa omisión no afecta la obligación de las entidades públicas de suministrar la información, dificulta el ejercicio del derecho

Más grave aún es el hecho que ningún poder del Estado ha conformado las OCAIP, lo que afecta el derecho de apelación en la vía administrativa. Sin duda alguna, el no contar con 
las estructuras que requiere la LAIP afecta su aplicación, pero hasta aquí hay un análisis eminentemente formal o jurídico que es el espíritu del trabajo.

Desde la aplicación práctica, sólo puedo hacer referencia a una medición hecha por la Fundación Violeta Barrios de Chamorro ${ }^{16}$ en una alianza con periodistas de diferentes medios de comunicación. Se realizaron diez solicitudes escritas, de las cuales cuatro simplemente fueron ignoradas, dos denegadas y tres respondidas positivamente entre febrero y mayo de 2008. El problema práctico que identifico es que no existe una vocación de servicio público en nuestros funcionarios, quienes no distinguen que trabajan para el pueblo nicaragüense y no para un proyecto político-partidario.

No obstante, a partir del 9 de julio de 2008, el nuevo Código Penal, de conformidad al Arto. 443 contempla como delito la denegación de acceso a la información pública. Consecuentemente, la autoridad, funcionario o empleado público que, fuera de los casos establecidos por la Ley (información privada e información reservada), deniegue o impida el acceso a la información pública requerida, será sancionado con pena de seis meses a dos años de prisión, e inhabilitación de uno a dos años para el ejercicio de empleo o cargo público. Esperemos que esta nueva herramienta jurídica rompa con el secretismo gubernamental y nos demos cuenta al fin cuánto dinero viene de la cooperación venezolana y cómo se está utilizando.

\section{Notas}

1 Arto. 4, Inciso a. Ley 621, Ley de Acceso a la Información Pública. La Gaceta Diario Oficial No 118 del 22 de junio de 2007.

2 Arto. 16, Inciso a. Ley 621, Ley de Acceso a la Información Pública. La Gaceta Diario Oficial No 118 del 22 de junio del 2007.

3 Arto. 26. Ley 621, Ley de Acceso a la Información Pública. La Gaceta Diario Oficial No 118 del 22 de junio del 2007.

4 Ibid.: Arto. 27.

5 Arto. 28. Ley 621, Ley de Acceso a la Información Pública. La Gaceta Diario Oficial No 118 del 22 de junio del 2007.

6 Arto. 37. Ley 621, Ley de Acceso a la Información Pública. La Gaceta Diario Oficial No 118 del 22 de junio del 2007.

7 Ibid.: Arto. 37.

8 Arto. 6. Ley 621, Ley de Acceso a la Información Pública. La Gaceta Diario Oficial No 118 del 22 de junio del 2007.

9 Arto. 26. Ley 350. Ley de Regulación de la Jurisdicción del lo Contencioso-Administrativo. La Gaceta Diario Oficial No 140 y 141 del 25 y 26 de julio del 2000. Esta ley tiene varios artículos declarados inconstitucionales por la sentencia No 40 de la CSJ del 10 de junio del 2002, a consecuencia de ello son inaplicables.

10 Arto. 50. Ley 350. Ley de Regulación de la Jurisdicción del lo Contencioso-Administrativo. La Gaceta Diario Oficial No 140 y 141 del 25 y 26 de julio del 2000.

11 Arto. 94. Ley 260. Ley Orgánica del Poder Judicial. La Gaceta Diario Oficial No 137 del 23 de julio de 1998.

12 Arto. 52. Ley 350. Ley de Regulación de la Jurisdicción del lo Contencioso-Administrativo. La Gaceta Diario Oficial No 140 y 141 del 25 y 26 de julio del 2000.

13 Arto. 60. Ley 350. Ley de Regulación de la Jurisdicción del lo Contencioso-Administrativo. La Gaceta Diario Oficial No 140 y 141 del 25 y 26 de julio del 2000.

14 Ibid.: Arto. 61.

15 Arto. 73. Ley 350. Ley de Regulación de la Jurisdicción del lo Contencioso-Administrativo. La Gaceta Diario Oficial No 140 y 141 del 25 y 26 de julio del 2000.

16 Disponible en http//www.violetachamorro.org.ni 


\section{Referencias bibliográficas}

GONZÁLEZ PÉREZ, J. (1992), Manual de derecho procesal administrativo. Madrid: Civitas. 2da ed.

MARTÍNEZ MORALES, R. (2000) Derecho administrativo, 3ro y 4to Curso. México: Oxford University Press. Tercera Edición.

PICONE, F. H. (1982) Elementos del derecho administrativo y el derecho procesal administrativo. Buenos Aires:Ediciones Macchi.

PIERINI, A. \& LORENCES, V. (1999) Derecho de acceso a la información. Buenos Aires: Editorial Universidad.

SENDRA, V. G. ET AL. (1991) Derecho procesal administrativo. Valencia: Tirant lo Blanch..

VILLANUEVA, E. (2003) El derecho de acceso a la información pública en Latinoamérica: Estudio introductorio y complicación. México DF: Universidad Nacional Autónoma de México. 